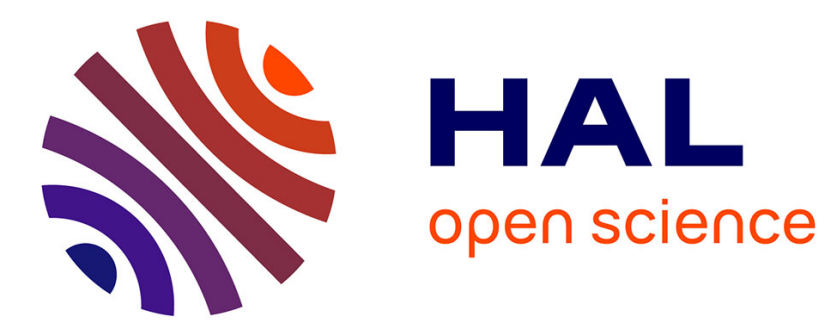

\title{
Relations between structural parameters and physical properties in CdTe and Cd0.96Zn0.04Te alloys
}

\author{
K. Guergouri, Y. Marfaing, R. Triboulet, A. Tromson-Carli
}

\section{To cite this version:}

K. Guergouri, Y. Marfaing, R. Triboulet, A. Tromson-Carli. Relations between structural parameters and physical properties in CdTe and Cd0.96Zn0.04Te alloys. Revue de Physique Appliquée, 1990, 25

(6), pp.481-488. 10.1051/rphysap:01990002506048100 . jpa-00246209

\section{HAL Id: jpa-00246209 \\ https://hal.science/jpa-00246209}

Submitted on 1 Jan 1990

HAL is a multi-disciplinary open access archive for the deposit and dissemination of scientific research documents, whether they are published or not. The documents may come from teaching and research institutions in France or abroad, or from public or private research centers.
L'archive ouverte pluridisciplinaire HAL, est destinée au dépôt et à la diffusion de documents scientifiques de niveau recherche, publiés ou non, émanant des établissements d'enseignement et de recherche français ou étrangers, des laboratoires publics ou privés. 


\title{
Relations between structural parameters and physical properties in CdTe and $\mathrm{Cd}_{0.96} \mathrm{Zn}_{0.04} \mathrm{Te}$ alloys
}

\author{
K. Guergouri, Y. Marfaing, R. Triboulet and A. Tromson-Carli \\ Laboratoire de Physique des Solides de Bellevue, C.N.R.S., F-92195 Meudon, France
}

(Reçu le 17 octobre 1989, accepté le 8 mars 1990)

\begin{abstract}
Résumé. - Des mesures électriques et des expériences de photoluminescence ont été réalisées sur des cristaux de $\mathrm{CdTe}$ et de $\mathrm{Cd}_{0,96} \mathrm{Zn}_{0,04} \mathrm{Te}$, de densité de dislocations variant entre $5 \times 10^{4}$ et $6 \times 10^{5} \mathrm{~cm}^{-2}$. La variation de la mobilité électronique a été interprétée en termes de : diffusion sur les régions de charge d'espace entourant les dislocations, réduction correspondante du volume effectif des cristaux, diffusion en excès dans les alliages due à leur caractère non idéal. La largeur de raie de recombinaison d'excitons liés à des accepteurs neutres se décompose en contributions associées au désordre d'alliage et aux dislocations, cette dernière étant augmentée dans les alliages.
\end{abstract}

\begin{abstract}
Electrical measurements and photoluminescence experiments were performed on several CdTe and $\mathrm{Cd}_{0.96} \mathrm{Zn}_{0.04} \mathrm{Te}$ crystals with dislocation density in the range $5 \times 10^{4}-6 \times 10^{5} \mathrm{~cm}^{-2}$. The observed variation in electron mobility has been interpreted in terms of scattering on space charge regions surrounding dislocations, a related reduction in the effective volume of the crystals, and excess scattering due to a non ideal alloy behaviour. The linewidth of the acceptor-bound exciton recombination line includes contributions due to alloy disorder and dislocations, the latter being enhanced in the alloys.
\end{abstract}

\section{Introduction.}

While the electronic properties of CdTe have been investigated for a long time, systematic studies related to the crystalline quality are rather recent : they mostly derive from the interest in $\mathrm{CdTe}$ as a substrate for the epitaxy of $\mathrm{CdHgTe}$ alloys. Then it has been realized that the crystalline quality of $\mathrm{CdTe}$ could be signifiantly improved by the addition of $\mathrm{Zn}$ atoms in the compound [1-3]. On the other hand the crystal lattice parameter decreases as $\mathrm{Zn}$ is incorporated so that an atomic $\mathrm{Zn}$ concentration of $4 \%$ allows a perfect lattice match with the alloy $\mathrm{Cd}_{0.2} \mathrm{Hg}_{0.8} \mathrm{Te}$ which is the composition needed for infrared detection in the common 8-12 $\mu \mathrm{m}$ wavelength range.

The better crystalline quality of $\mathrm{CdZnTe}$ alloys compared to CdTe has been analysed by various workers in terms of bond stabilization [4, 5] and solution hardening [6]. Experiments on plastic deformation and microhardness measurements [6] have shown that the crystal lattice is actually made harder by the presence of $\mathrm{Zn}$, in fair agreement with the model first applied to GaAs : In [7].

Little attention has been paid to the physical properties of $\mathrm{ZnCdTe}$ alloys. However some physical parameters are quite sensitive to the presence of structural defects and could be used as a complementary way for assessing the crystalline quality of the material.

In this paper we present a study of electrical and luminescence properties of $\mathrm{CdZnTe}$ alloys compared to CdTe. From the analysis of electron mobility and excitonic luminescence spectra it is shown that useful and interesting correlations can be established between physical quantities and structural parameters. This leads to a better understanding of the influence of crystalline defects on the electronic properties of semiconductors.

\section{Experimental.}

All the crystals studied were grown using the modified vertical Bridgman method [8]. The $\mathrm{Cd}$ vapour pressure above the melt was controlled with a $\mathrm{Cd}$ reservoir to make the crystals electrically conductive n-type.

Several crystals were grown with different growth parameters which led to crystals of variable quality. Five representative crystals were selected for this 
Table I. - Dislocation density $\left(N_{\mathrm{d}}\right)$ and X-ray rocking curve linewidth $\left(\Delta_{\mathrm{RC}}\right)$ of the investigated crystals.

\begin{tabular}{|c|r|c|c|c|c|}
\hline & $\begin{array}{c}\mathrm{C} 4 \\
\mathrm{CdTe}\end{array}$ & $\begin{array}{c}\mathrm{C} 3 \\
\mathrm{CdZnTe}\end{array}$ & $\begin{array}{c}\mathrm{C6} \\
\mathrm{CdZnTe}\end{array}$ & $\begin{array}{c}\mathrm{C} 2 \\
\mathrm{CdZnTe}\end{array}$ & $\begin{array}{c}\mathrm{C} 11 \\
\text { CdZnTe }\end{array}$ \\
\hline$x \%$ & 0 & 3.4 & 3.2 & 3.3 & 2.7 \\
\hline $\begin{array}{c}N_{\mathrm{d}} \\
\left(10^{5} \mathrm{~cm}^{-2}\right)\end{array}$ & 5 & 0.5 & 0.8 & 3 & 6.2 \\
\hline $\begin{array}{c}\Delta_{\mathrm{RC}} \\
(\operatorname{arc} . \sec )\end{array}$ & 100 & 25 & 30 & 70 & 250 \\
\hline
\end{tabular}

study. They are indicated in table I with the corresponding chemical and structural characteristics. The $\mathrm{Zn}$ composition was deduced from photoluminescence experiments (see below). The etch pit density $\mathrm{N}_{\mathrm{d}}$ was determined by using the $\mathrm{E}-\mathrm{A}_{\mathrm{g}}$ Inoue etch [9] on a (111) Cd face. The rocking curve width $\Delta_{\mathrm{RC}}$ was measured from the (333) $\mathrm{X}$ ray reflection. Figure 1 shows that $\Delta_{\mathrm{RC}}$ is proportional to the square root of the dislocation density in agreement with the model of Gay et al. [10] which gives confidence in the structural measurements. The point corresponding to crystal $\mathrm{C} 11$ has been disregarded because of some error or artefact in the measurement of $\Delta_{\mathrm{RC}}$. provided by the $488 \mathrm{~nm}$ line of an $\mathrm{Ar}^{+}$laser. The power density on the samples was about $50 \mathrm{~W} \mathrm{~cm}^{-2}$. Luminescence analysis was done with a $1 \mathrm{~m}$ Jobin Yvon monochromator followed by a cooled GaAs photomultiplier.

\section{Electrical properties.}

The variations of electron mobility and carrier concentration are shown in figures 2 and 3 as a function of temperature for four crystals (C11 was semi insulating). The room temperature values are collected in table II.

The temperature dependence of carrier concentration was fitted by postulating the semiconductor is compensated. In this way we determine the donor ionization energy $E_{\mathrm{D}}$ and the concentration of donor and acceptor impurities, the values of which are given in table II. The measured samples show two distinct behaviours. A small ionization energy is determined for samples $\mathrm{C} 2$ and $\mathrm{C} 4$ in the range expected for effective mass donors. Samples C3 and C6 exhibit deeper donor levels which should be attributed to impurity complexes.

The analysis of electron mobility was conducted along the following lines. First, theoretical values of mobility $\mu_{\mathrm{T}}$ were calculated by combining the effects

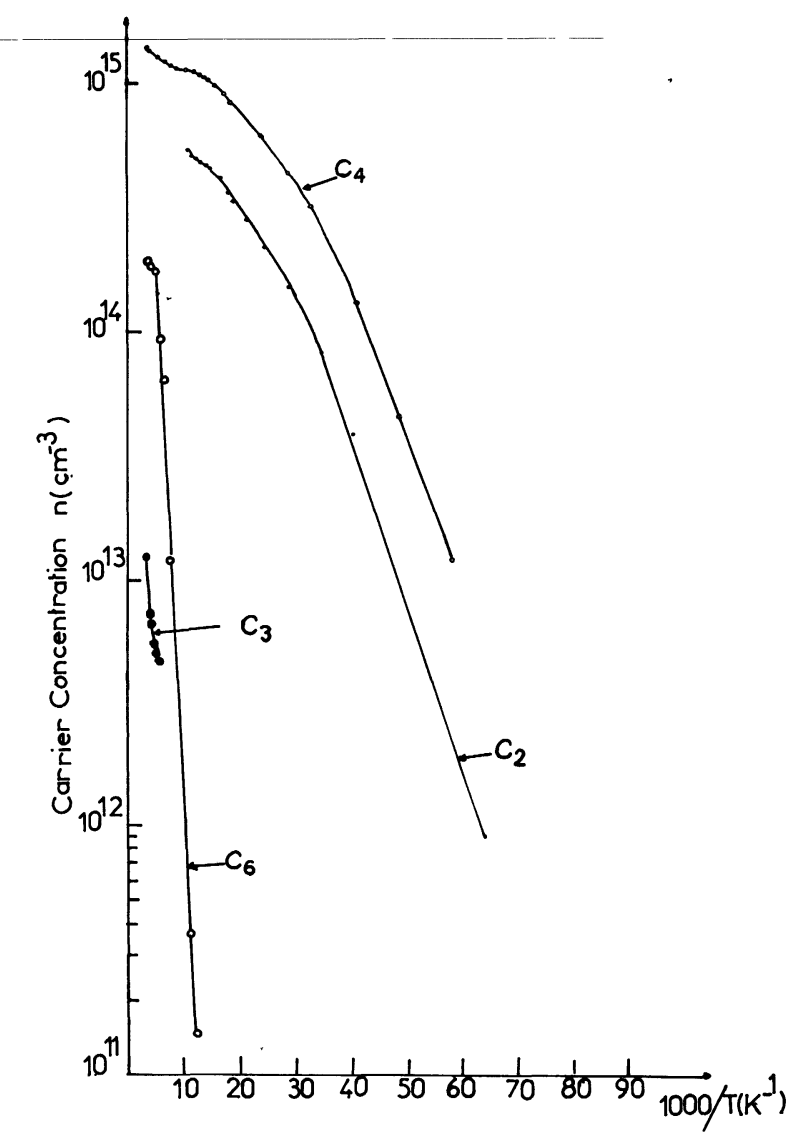

Fig. 2. - Electron concentration as a function of temperature as deduced from Hall measurements.
Fig. 1. - Double crystal rocking curve width $\Delta_{\mathrm{RC}}$ as a function of the square root of the dislocation density.

Resistivity and Hall effect measurements were performed as a function of temperature using standard techniques.

Photoluminescence experiments were carried out at the temperature of $2 \mathrm{~K}$. Excitation light was 


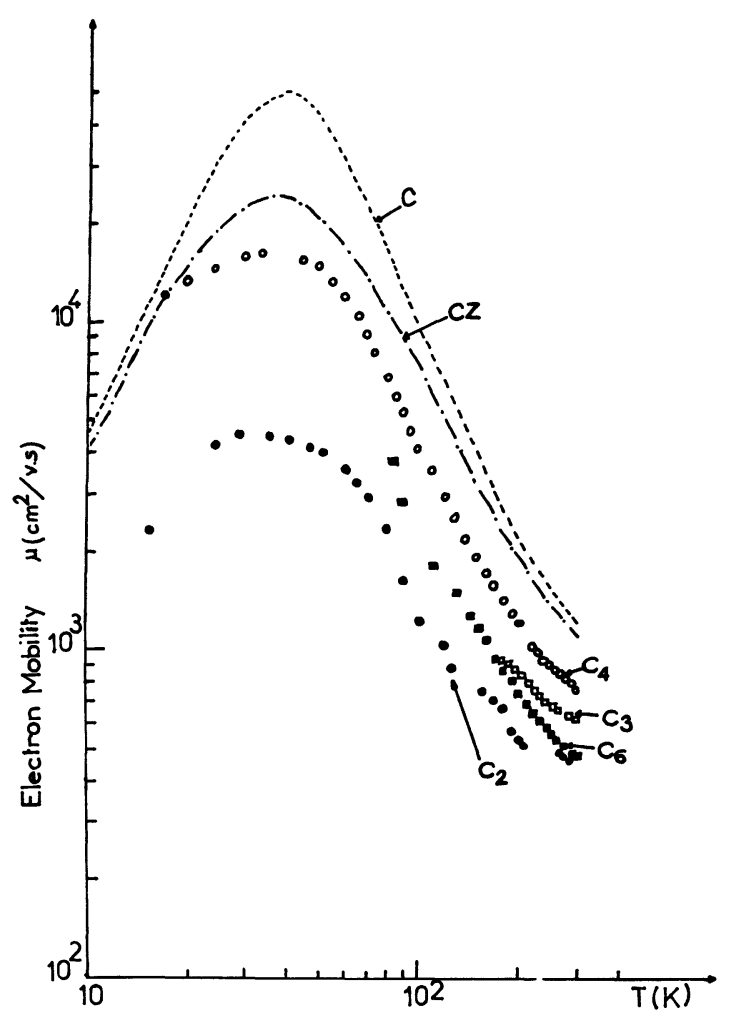

Fig. 3. - Electron mobility as a function of temperature as deduced from Hall and resistivity measurements. $\mathrm{C}$ and $\mathrm{CZ}$ designate the theoretical mobility $\mu_{\mathrm{T}}$ calculated from formula (1) for CdTe and CdZnTe alloys respectively. of various scattering mechanisms: polar optical scattering $\left(\mu_{0}\right)$, scattering on neutral impurities $\left(\mu_{N}\right)$ and on charged impurities $\left(\mu_{I}\right)$ disorder scattering (in case of alloys) $\left(\mu_{R}\right)$ :

$$
\frac{1}{\mu_{\mathrm{T}}}=\frac{1}{\mu_{0}}+\frac{1}{\mu_{\mathrm{N}}}+\frac{1}{\mu_{\mathrm{I}}}+\frac{1}{\mu_{\mathrm{R}}}
$$

The expressions of the first three terms were taken from Aleksenko et al. [11]. The last one is calculated from the formula [12]:

$$
\mu_{\mathrm{R}}=\frac{(2 \pi)^{1 / 2} e \hbar^{4} N_{\mathrm{s}}}{3(k T)^{1 / 2} m_{\mathrm{n}}^{5 / 2}\left(E_{1}-E_{2}\right)^{2} x(1-x)}
$$

$N_{\mathrm{s}}$ is the concentration of atomic sites $(2.94 \times$ $10^{22} \mathrm{~cm}^{-3}$ in $\left.\mathrm{CdTe}\right), e$ is the electronic charge, $m_{\mathrm{n}}$ is the electron mass, $E_{1}-E_{2}$ is the conduction band offset between $\mathrm{CdTe}$ and $\mathrm{ZnTe}$ taken to be $0.7 \mathrm{eV}$ [13].

The variations of the theoretical mobility $\mu_{\mathrm{T}}$ as a function of temperature are plotted in figure 3 with the parameters corresponding to sample $\mathrm{C} 4(\mathrm{CdTe}$, curve $\mathrm{C}$ ) and $\mathrm{C} 2$ ( $\mathrm{CdZnTe}$, curve $\mathrm{CZ})$. As these theoretical values are higher than the experimental ones, other mobility limiting processes have been considered. It is known that an inhomogeneous impurity distribution can greatly reduce the carrier mobility [14]. This is due to the formation of space

Table II. - Quantities determined from electrical measurements : $n$, electron concentration; $\mu_{\mathrm{ex}}$, electron mobility; $E_{\mathrm{D}}$, donor ionization energy; $N_{\mathrm{D}}\left(N_{\mathrm{A}}\right)$, donor (acceptor) concentration; $\mu_{\mathrm{i} 0}$, mobility related to excess scattering ; $f$, function of the relative volume occupied by inhomogeneities.

\begin{tabular}{|c|c|c|c|c|}
\hline & $\begin{array}{c}\mathrm{C} 4 \\
\mathrm{CdTe}\end{array}$ & $\begin{array}{c}\mathrm{C} 3 \\
\mathrm{CdZnTe}\end{array}$ & $\begin{array}{c}\mathrm{C} 6 \\
\mathrm{CdZnTe}\end{array}$ & $\begin{array}{c}\mathrm{C} 2 \\
\mathrm{CdZnTe}\end{array}$ \\
\hline $\begin{array}{c}n(300 \mathrm{~K}) \\
\mathrm{cm}^{-3}\end{array}$ & $1.37 \times 10^{15}$ & $1.2 \times 10^{13}$ & $1.89 \times 10^{14}$ & $5.02 \times 10^{14}$ \\
\hline $\begin{array}{c}\mu_{\mathrm{ex}}(300 \mathrm{~K}) \\
\mathrm{cm}^{2} \mathrm{~V}^{-1} \mathrm{~s}^{-1}\end{array}$ & 750 & 600 & 460 & 450 \\
\hline $\begin{array}{c}E_{\mathrm{D}} \\
\mathrm{meV}\end{array}$ & 7.5 & 43 & 88 & 9.1 \\
\hline $\begin{array}{c}N_{\mathrm{D}} \\
\mathrm{cm}^{-3}\end{array}$ & $1.31 \times 10^{15}$ & & & $7.43 \times 10^{14}$ \\
\hline $\begin{array}{c}N_{\mathrm{A}} \\
\mathrm{cm}^{-3}\end{array}$ & $1.67 \times 10^{14}$ & & 2040 & $2.43 \times 10^{14}$ \\
\hline $\begin{array}{c}\mu_{\mathrm{i} 0} \\
\mathrm{~cm}^{2} \mathrm{~V}^{-1}\end{array}$ & 4000 & 3030 & 0.64 & 2000 \\
\hline$f$ & 0.44 & 0.74 & & 0.63 \\
\hline
\end{tabular}


charge regions surrounding local inhomogeneities. In the case these defects in concentration $N_{\mathrm{i}}$ are separated by a distance smaller than the electron mean free path they determine a mobility given by :

$$
\begin{aligned}
& \mu_{\mathrm{i}}=A N_{\mathrm{i}}^{-1} T^{-5 / 6} \\
& \mu_{\mathrm{i}}=\mu_{\mathrm{i} 0}\left(\frac{T}{300}\right)^{-5 / 6} .
\end{aligned}
$$

Furthermore, because of the strong electric fields present in the space charge regions the latter can be regarded as impenetrable for electrons and a correction has to be brought to the volume of the crystal. Therefrom the experimental mobility is given by :

$$
\mu_{\mathrm{ex}}=\frac{1}{\frac{1}{\mu_{\mathrm{T}}}+\frac{1}{\mu_{\mathrm{i}}}} \cdot f(\varepsilon)
$$

where $\varepsilon$ is the relative volume occupied by inhomogeneities and $f$ is a function of this volume : $f<1$ [15].

The adjustment of this expression to the experimental curves gives the values of the quantities $\mu_{\mathrm{i} 0}$ and $f$ gathered in table II.

\section{Luminescence properties.}

The low temperature photoluminescence spectra recorded on crystals $\mathrm{C} 4, \mathrm{C} 3$ and $\mathrm{C} 11$ are presented as examples in figures 4-6. These spectra exhibit typical exciton-related recombination lines: free exciton (X), exciton bound to neutral donors $\left(D^{0} X\right)$, exciton bound to neutral acceptors $\left(A^{0} X\right)$, optical phonon replica of the free exciton $(X-$ LO) and of the acceptor-bound exciton $\left(A^{0} X-L O\right)$; two electron transitions $\left(D_{2}\right)$ seen on

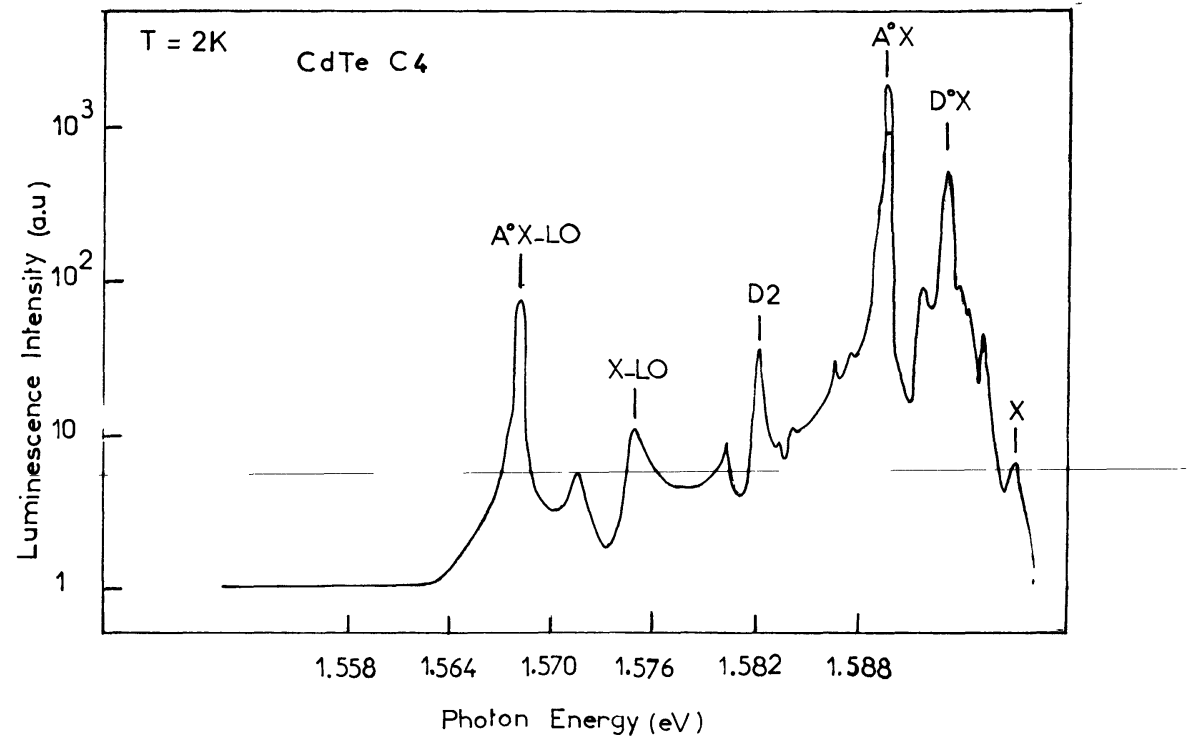

Fig. 4. - Low temperature photoluminescence spectrum of CdTe sample C4.

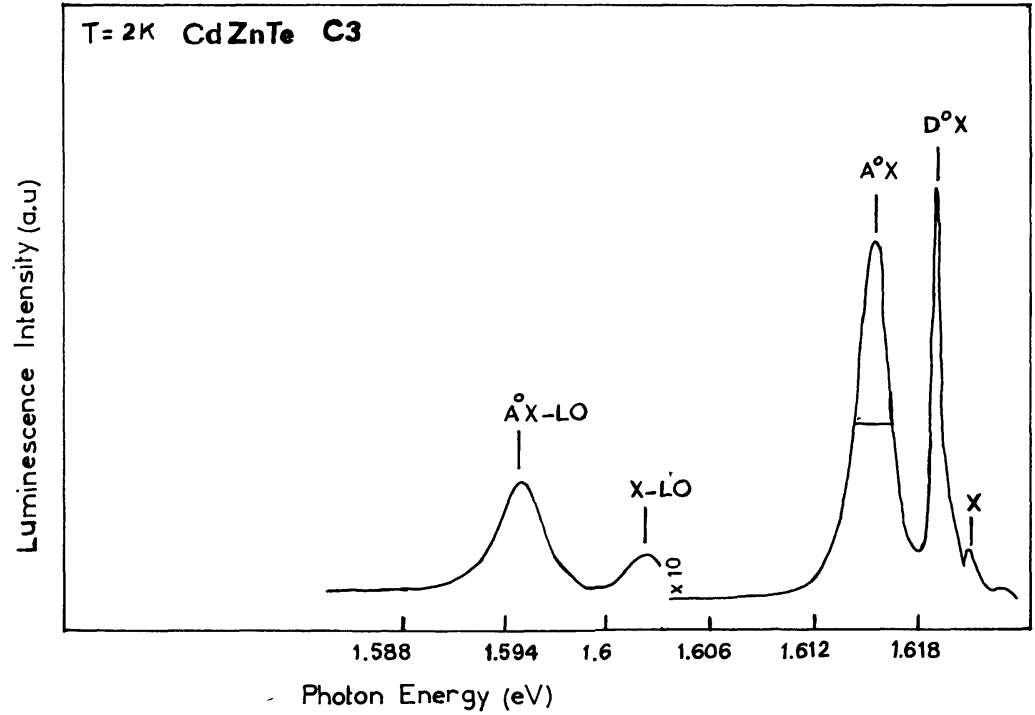

Fig. 5. - Low temperature photoluminescence spectrum of CdZnTe sample C3 with dislocation density $N_{\mathrm{d}}=5 \times 10^{4} \mathrm{~cm}^{-2}$. 


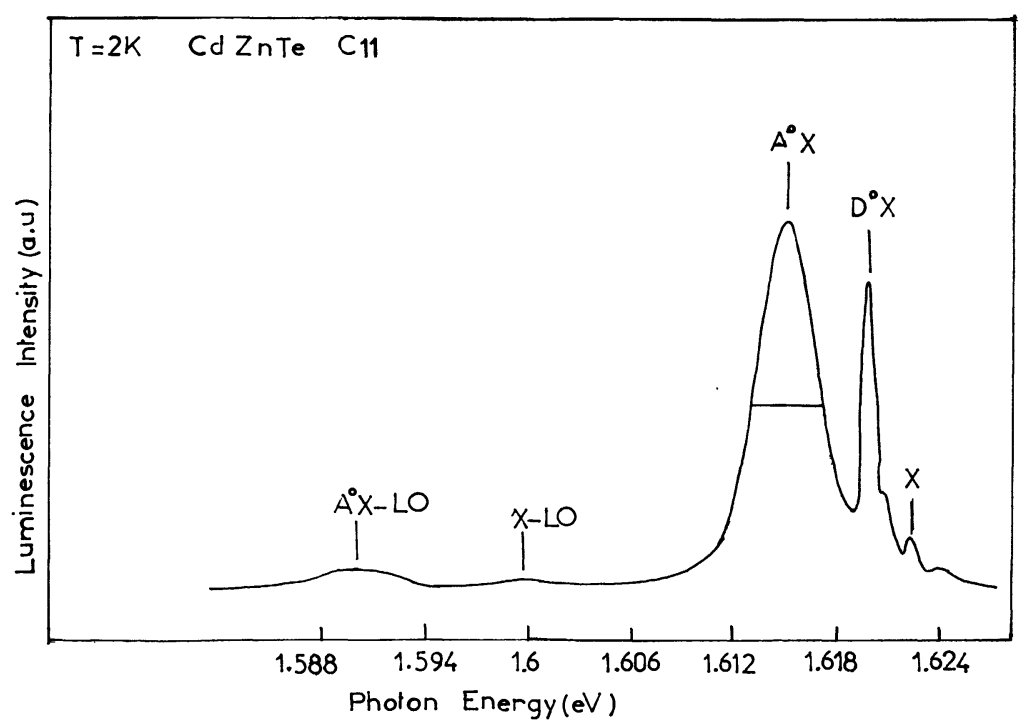

Fig. 6. - Low temperature photoluminescence spectrum of $\mathrm{CdZnTe}$ sample $\mathrm{Cl1}$ with dislocation density $N_{\mathrm{d}}=6.2 \times 10^{5} \mathrm{~cm}^{-2}$.

CdTe only. The free exciton position can be used in conjunction with the variation of band gap as function of alloy composition [16] to determine the exact value of $\mathrm{Zn}$ concentration in the studied alloys. These composition values appear in table I.

A striking feature of the above photoluminescence spectra is the broadening of the $\mathrm{A}^{0} \mathrm{X}$ line in the alloys. The full width at half maximum (FWHM) of the $\mathrm{A}^{0} \mathrm{X}$ line is given in table III for the five crystals studied. The contribution of alloy disorder to this broadening can be evaluated with a model due to Goede et al. [17] and others [18]. This model starts from the mean alloy fluctuation in the volume $V_{\mathrm{X}}$ occupied by the excitons :

$$
\sigma_{\mathrm{X}}=\left(\frac{x(1-x)}{K V_{\mathrm{X}}}\right)^{1 / 2}
$$

where $K$ is the concentration of cation sites in the

Table III. - Linewidth parameters for the acceptorbound exciton photoluminescence line: FWHM, measured width value at half maximum; $\Delta E_{\mathrm{R}}$, calculated contribution due to alloy disorder; $\Delta E_{\mathrm{c}}$, remaining contribution.

\begin{tabular}{|c|c|c|c|c|c|}
\hline & $\begin{array}{c}\mathrm{C} 4 \\
\mathrm{CdTe}\end{array}$ & $\begin{array}{c}\mathrm{C} 3 \\
\text { CdZnTe }\end{array}$ & $\begin{array}{c}\mathrm{C} 6 \\
\text { CdZnTe }\end{array}$ & $\begin{array}{c}\mathrm{C} 2 \\
\text { CdZnTe }\end{array}$ & $\begin{array}{c}\mathrm{C} 11 \\
\text { CdZnRe }\end{array}$ \\
\hline $\begin{array}{c}\text { FWHM } \\
\mathrm{meV}\end{array}$ & 0.35 & 2.45 & 2.8 & 3.3 & 3.5 \\
\hline $\begin{array}{c}\Delta E_{\mathrm{R}} \\
\mathrm{meV}\end{array}$ & 0 & 2.17 & 2.12 & 2.11 & 1.95 \\
\hline $\begin{array}{c}\Delta E_{\mathrm{c}} \\
\mathrm{meV}\end{array}$ & 0.35 & 1.14 & 1.83 & 2.53 & 2.9 \\
\hline
\end{tabular}

crystals $\left(1.47 \times 10^{22} \mathrm{~cm}^{-3}\right.$ in CdTe $)$. We consider the space occupied by the acceptor-bound exciton to be a sphere of volume :

$$
V_{\mathrm{X}}=\frac{4}{3} \pi\left[\left(\frac{m_{0}}{\mu}+\frac{m_{0}}{m_{\mathrm{p}}}\right) \varepsilon_{\mathrm{r}} a_{\mathrm{B}}\right]^{3}
$$

where $m_{0}, \mu, m_{\mathrm{p}}$ are the free electron mass, the reduced exciton mass and the effective hole mass. $\varepsilon_{\mathrm{r}}$ is the static dielectric constant and $\mathrm{a}_{\mathrm{B}}$ is the hydrogen Bohr radius. The sphere radius is thus expressed as the sum of the free exciton radius and of the neutral acceptor Bohr radius. Then the standard deviation of energy gap $E_{\mathrm{g}}$ is the volume $V_{\mathrm{X}}$ is :

$$
\sigma_{\mathrm{E}}=\frac{\mathrm{d} E_{\mathrm{g}}}{\mathrm{d} x}\left[\frac{x(1-x)}{K V_{\mathrm{X}}}\right]^{1 / 2} .
$$

For a Gaussian distribution the full width at half maximum is 2.36 times this standard deviation. We take this quantity $\Delta E_{\mathrm{R}}=2.36 \sigma_{\mathrm{E}}$ to represent the part of the $\mathrm{A}^{0} \mathrm{X}$ line broadening due to disorder. Table III gives the values of $\Delta E_{\mathrm{R}}$ calculated with the following parameters: $\mu / m_{0}=0.083 ; m_{\mathrm{p}} / m_{0}=$ $0.6 ; \varepsilon_{\mathrm{r}}=10.2 ; \mathrm{d} E_{\mathrm{g}} / \mathrm{d} x=0.8 \mathrm{eV}$. These values can now be substracted from the experimental FWHM to yield the excess broadening $\Delta E_{\mathrm{c}}$ :

$$
\Delta E_{\mathrm{c}}=\left[(\mathrm{FWHM})^{2}-\left(\Delta E_{\mathrm{R}}\right)^{2}\right]^{1 / 2} .
$$

The quantities $\Delta E_{\mathrm{c}}$ are also indicated in table III.

\section{Discussion.}

We now intend to relate the physical parameters determined from the electrical and luminescence measurements to the structural characteristics of the 
crystals, essentially the density of dislocations (Tab. I).

As for the electrical measurements a representative parameter is $\varepsilon$, the relative volume occupied by the regions impenetrable to electrons. Assuming spherical regions, $\varepsilon$ is deduced from the factor $f$ in table II by the expression [14] :

$$
f(\varepsilon)=\frac{1-\varepsilon}{1+\varepsilon / 2}
$$

$\varepsilon$ increases as the density of dislocations increases as shown in figure 7. This relationship includes the alloys as well as CdTe. Thus it appears that the space charge regions surrounding dislocations are a major contribution to the reduction in the effective volume of the crystals.

Inhomogeneities also lead to an excess scattering represented by the mobility $\mu_{i}$ (3). After relations (3) and (4) $\mu_{\mathrm{i} 0}^{-1}$ is proportionnal to the concentration of scattering centers. Figure 8 shows the plot of $\mu_{\mathrm{i} 0}^{-1}$ as a function of the density of dislocations. The quantity $\mu_{\mathrm{i} 0}^{-1}$ tends to increase with increasing

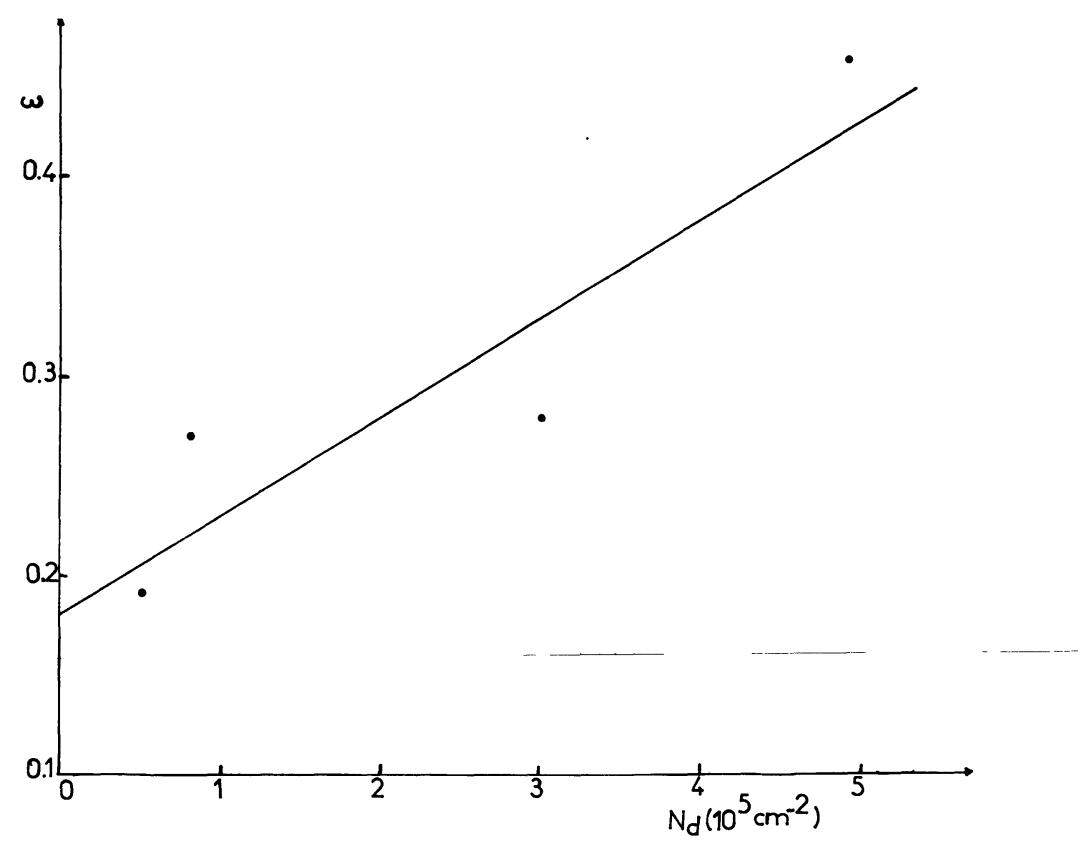

Fig. 7. - Relative volume $\varepsilon$ occupied by regions impenetrable to electrons as a function of dislocation density.

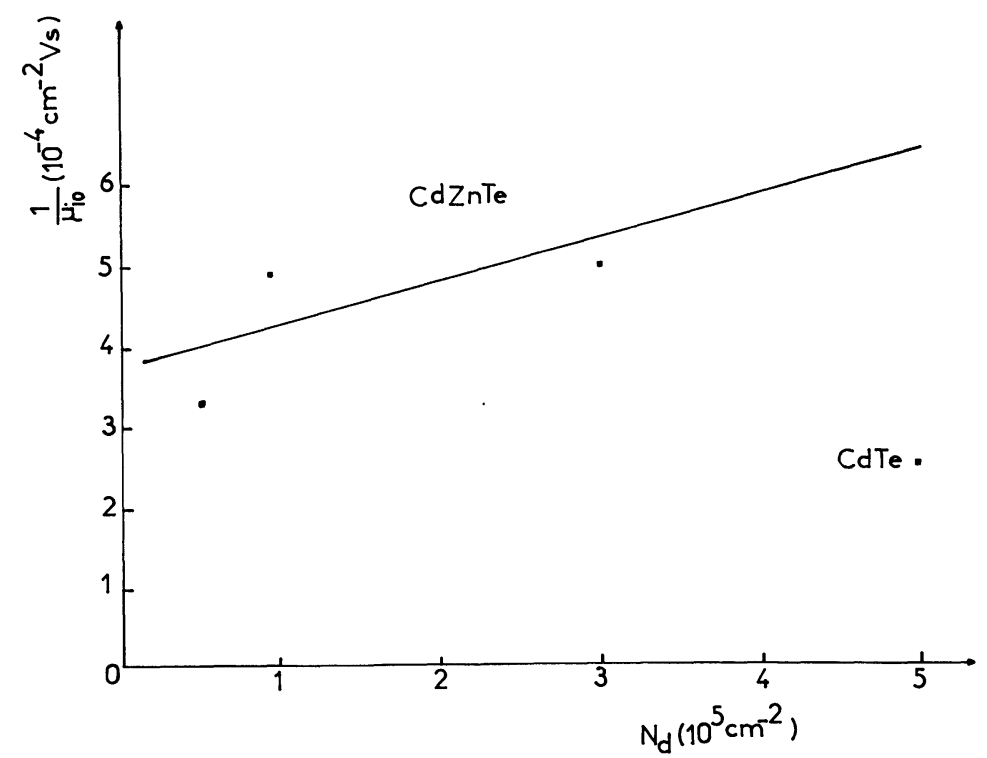

Fig. 8. - Relation between the room temperature mobility $\mu_{10}$ limited by scattering on inhomogeneities and the dislocation density $N_{\mathrm{d}}$. 


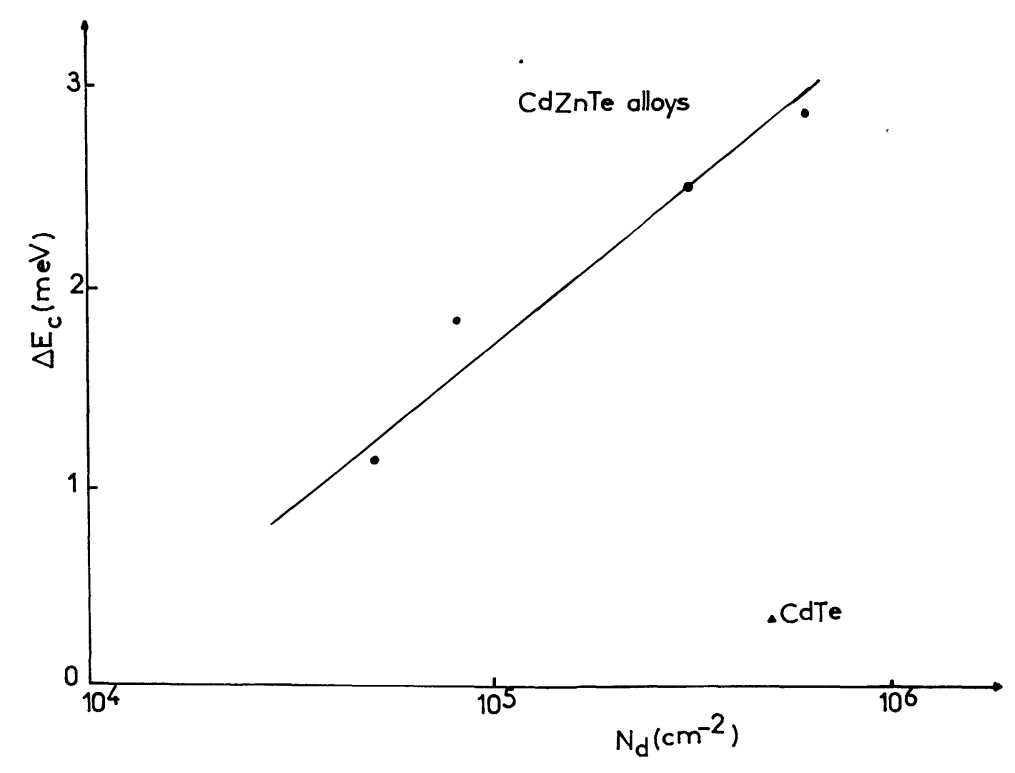

Fig. 9. - Linewidth of the $\mathrm{A}^{0} \mathrm{X}$ recombination line $\Delta E_{\mathrm{c}}$ (corrected from alloy disorder) as a function of dislocation density.

$N_{\mathrm{d}}$ in the alloys as shown by the best fitted straight line. However the main source of scattering does not depend on dislocation density and could be related to specific effects such as local strains and alloy clustering. The quantity determined for $\mathrm{CdTe}$ does not include this contribution and is due solely to dislocations. That particular value of $2.5 \times$ $10^{-4} \mathrm{~cm}^{-2} \mathrm{~V}$.s appears to be in agreement with the value deduced from the straight line after substracting the part due to alloying $\left(N_{\mathrm{d}}=0\right)$. Thus the relation of figure 8 can be taken at a first approximation to express the effect of dislocations on scattering in the alloys as well as in CdTe.

As for the optical measurements the significant parameter is the width of the bound exciton recombination line $\mathrm{A}^{0} \mathrm{X}$. For the alloys the linewidth $\Delta E_{\mathrm{C}}$ determined after deduction of the contribution due to disorder increases with the density of dislocations as shown in figure 9. However this relation does not account for the linewidth found in CdTe. Note that the latter is representative of a material of standard quality. Higher quality CdTe shows an $\mathrm{A}^{0} \mathrm{X}$ linewidth as low as $0.1 \mathrm{meV}$ [19].

It appears that the optical properties of the alloys are more sensitive to the presence of dislocations than the compound CdTe. Again this could be related to the non ideal character of the alloys, e.g. some kind of interaction between $\mathrm{Zn}$ clusters and dislocations.

\section{Conclusion.}

The electronic properties of $\mathrm{Zn}_{x} \mathrm{Cd}_{1-x} \mathrm{Te}$ alloys with $x$ around $4 \%$ have been analysed and related to the dislocation density. Several physical effects have been demonstrated. The space charge regions surrounding dislocations reduce the conducting volume of the crystals which leads to a smaller effective mobility. This effect has been separated from the dislocation induced scattering process affecting the electron mean free path.

Moreover the linewidth of the bound exciton recombination lines increases rapidly with the density of dislocations which could be related to the associated strain field. The same types of effects are also found in the compound CdTe. However the alloys exhibit additional contributions besides that due to alloy disorder. We suggest that these extra contributions could originate from aspects not included in the analysis of ideal alloys, such as local strains due to bond length misfit and $\mathrm{Zn}$ clustering. Deviation from a random distribution of substituted $\mathrm{Zn}$ atoms in CdZnTe was indeed observed in recent NMR experiments [20].

\section{References}

[1] James R. W. and Stoller R. E., Appl. Phys. Lett. 44 (1984) 56 ;

Bell S. L. and Sen S., J. Vac. Sci. Technol. A 3 (1985) 112.

[2] Woolhouse G. R., Magee T. J., Kawayoshi H.
A., LeUnG C. S. H. and ORMOND R. D., J. Vacuum Sci. Technol. A 3 (1985) 83.

[3] Tranchart J. C., Latorre B., Foucher C. and Le Gouge Y., J. Cryst. Growth 72 (1985) 468 ; Yoshikawa M., Maruyama K., Saito T., Maeka- 
wa T. and Takigawa H., J. Vac. Sci. Technol. A 5 (1987) 3052.

[4] Sher A., Chen A. B. and SpICer W. E., Appl. Phys. Lett. 46 (1985) 54 ;

Sher A., Chen A. B., Spicer W. E. and Shih C. K., J. Vacuum Sci. Technol. A 3 (1985) 105.

[5] Triboulet R., J. Cryst. Growth 86 (1988) 79.

[6] Guergouri K., Triboulet R., Tromson-Carli A. and Marfaing Y., J. Cryst. Growth 86 (1988) 61.

[7] Ehrenreich H. and Hirth J. P., Appl. Phys. Lett. 46 (1985) 668.

[8] Triboulet R. and Marfaing Y., J. Electrochem. Soc. 120 (1973) 1260.

[9] Inoue M., Teramoto I. and Takayanagi S., $J$. Appl. Phys. 33 (1962) 2578.

[10] Gay P., Hirsch P. B. and Kelly A., Acta Met. 1 (1953) 315.

[11] Alekseenko M. V., Arkad'eva E. N. and MatveEv O. A., Sov. Phys. Semicond. 4 (1970) 349.
[12] Stringfellow G. B., J. Appl. Phys. 50 (1979) 6 ; SAXena A. K., Phys. Rev. B 24 (1981) 3295.

[13] Tran Minh Duc, Hsu C. and Faurie J. P., Phys. Rev. Lett. 58 (1987) 1127.

[14] Weisberg L. R., J. Appl. Phys. 33 (1962) 1817.

[15] JURETSCHKE H. J., LANDAUER R. and SWANSON J. A., J. Appl. Phys. 27 (1956) 838.

[16] Gross E. F., Grigorovich G. M., Pozdynyakov I. V., Sredin V. G. and Suslina L. G., Sov. Phys. Solid State 12 (1971) 2352.

[17] Goede O., John L. and HenNig D., Phys. Status Solidi B 89 (1978) K 183.

[18] Schubert E. F., Göbel E. O., Horikoshi Y., Ploog K. and Queisser H. J., Phys. Rev. B 30 (1984) 813.

[19] Triboulet R. and Marfaing Y., J. Cryst. Growth 51 (1981) 89 ;

Molva E., Chamonal J. P. and Pautrat J. L., Phys. Status Solidi B 109 (1982) 635.

[20] Beshah K., Zamir D., Becla P., WolfF P. A. and Griffin R. G., Phys. Rev. B 36 (1987) 6420. 